\title{
Relación entre miedo, trastornos de ansiedad y depresión en escolares en una escuela subvencionada de Asunción
}

\author{
Mercedes Jazmín Báez', Zunilda Vera', María Antonia Mendoza², \\ Carlos Miguel Ríos González²
}

\section{Resumen}

Introducción: El miedo es una reacción natural ante los peligros, se constituye como un elemento necesario en el desarrollo evolutivo de las personas, es decir cumple un factor adaptativo ante amenazas reales o imaginarias. Puede convertirse en uno de los aspectos más perturbadores de la vida de las personas al construir la base de fobias y otros trastornos de ansiedad y depresiones.

La ansiedad es una emoción normal presente a lo largo del desarrollo del individuo, cuya función es la de protección, es una reacción anticipada ante una amenaza o peligro real o imaginario, es decir un trastorno caracterizado por un medio irracional y desproporcionado, no apropiado para el nivel de desarrollo del individuo. En niños y adolescentes la alteración afecta las esferas social, escolar y familiar. La depresión es un trastorno mental caracterizado por la presencia de tristeza y apatía, anhedonia, falta de autoestima, trastorno de sueño y el apetito, sensación de cansancio y falta de concentración.

Objetivo: Determinar la relación entre el miedo, trastornos de ansiedad y depresión en niños y niñas que asisten a una escuela subvencionada de la ciudad de Asunción

Material y Método: Se realizó un estudio cuantitativo, no experimental, correlacional, de corte transversal con muestreo no probabilístico de tipo intencional. Fueron incluidos niños de 6 a 12 años, alumnos de una escuela subvencioanda en el bariio Republicano de Asunción. Para la recolección de datos se utilizó la RCADS (Revised Child Anxiety and Depression Scale) en versión española abreviada con 30 ítems.

Resultados: En el estudio fueron incluidos 100 escolares de los cuales el 51\% (51) son de sexo masculino y el $48 \%$ (48) son de sexo femenino, la edad estuvo comprendida de 6 a 12 años $(M=8.59 ; \mathrm{DE}=1.64)$, siendo la mayoría de 8 y

\footnotetext{
1. Universidad Nihon Gakko. Facultad de Humanidades y Ciencias de la Educación, Paraguay.

2. Universidad Nihon Gakko, Dirección de Investigación, Paraguay.

E-mail: riosgonzalezcm@nihongakko.edu.py

DOI: $10.26885 /$ rcei.foro.2019.241
}

Trabajo publicado en acceso abierto bajo Licencia Creative Commons. 
9 años. La correlación fue estadísticamente significativa, positiva y moderada entre miedo y ansiedad $(r=.586 ; p=.000)$, entre miedo y depresión $(r=.456$; $p=.000)$, y entre ansiedad y depresión $(r=.493 ; p=.000)$. Estos resultados indican que a mayor nivel de miedo se presentará mayor nivel de ansiedad y mayor nivel de depresión, así como a mayor ansiedad se presentará mayor nivel de depresión.

Conclusión: La relación entre las principales variables fue significativa y positiva y moderada, tanto en las correlaciones entre miedo y ansiedad; miedo y depresión lo que significa que ante mayores manifestaciones de uno de los constructos se podría esperar mayores manifestaciones de otro.

Palabras clave: miedo, trastornos de ansiedad, depresión.

\section{Referencias}

André, C (2005). Psicología del miedo: temores angustias y fobias. Barcelona: Editorial Kairos.

Bados, A. (2005). Trastorno de la ansiedad por separación: rechazo escolar y fobia escolar. Barcelona: Universidad de Barcelona.

Del Barrio, M. (2000). La depresión infantil: factores de riesgo y posibles soluciones. Málaga: Aljibe.

García Fernández, J. M. (1997). Validación de tres formas del inventario de miedos escolares. Murcia: Universidad de Murcia.

Méndez, F. (2002). El niño que no sonríe: estrategias para superar la tristeza y la depresión infantil. España: Ediciones Pirámide. 